\title{
Design principles for establishing a multi-sided open innovation platform: lessons learned from an action research study in the medical technology industry
}

\author{
Christofer F. Daiberl ${ }^{1}$ (D) $\cdot$ Sascha Julian Oks ${ }^{1}$ (D) $\cdot$ Angela Roth $^{1}$ (D) $\cdot$ Kathrin M. Möslein $^{1,2}$ (D) $\cdot$ Steven $^{\text {Alter }}{ }^{3}$ (D)
}

Received: 19 October 2018 / Accepted: 28 November 2018/Published online: 17 January 2019

(C) The Author(s) 2019

\begin{abstract}
Innovation in the medical technology (med tech) industry has a major impact on well-being in society. Open innovation has the potential to accelerate the development of new or improved healthcare solutions. Building on work system theory (WST), this paper explores how a multi-sided open innovation platform can systematically be established in a German med tech industry cluster in situations where firms had no prior experience with this approach. We aim to uncover problems that may arise and identify opportunities for overcoming them. We performed an action research study in which we implemented and evaluated a multi-sided web-based open innovation platform in four real-world innovation challenges. Analyzing the four different challenges fostered a deeper understanding of the conceptual and organizational aspects of establishing the multi-sided open innovation platform as part of a larger work system. Reflecting on the findings, we developed five design principles that shall support the establishment of multi-sided open innovation platforms in other contexts. Thus, this paper contributes to both theory and practice.
\end{abstract}

Keywords Multi-sided platforms · Open innovation $\cdot$ Work system theory $\cdot$ Medical technology industry cluster $\cdot$ Action research

\section{JEL Classification M1}

\section{Introduction}

Innovation in the medical technology (med tech) industry is vital for the future of med tech firms and contributes to the health of society. The global med tech industry has significant opportunities to expand its sales to over USD 500 billion by 2021 (Japsen 2016). Demographic change and an altering

Responsible Editor: Ulrike E. Lechner

Christofer F. Daiberl

christofer.daiberl@fau.de

1 Chair of Information Systems, Innovation and Value Creation, Friedrich-Alexander-Universität Erlangen-Nürnberg, Lange Gasse 20, 90403 Nuremberg, Germany

2 CLIC - Center for Leading Innovation \& Cooperation, HHL Leipzig Graduate School of Management, Jahnallee 59, 04109 Leipzig, Germany

3 University of San Francisco, 2130 Fulton Street, San Francisco, CA, USA attitude toward the meaning of "being healthy" creates an ever-increasing demand for new or improved healthcare solutions (BVMed 2013). Despite these opportunities, increasing global competition, higher customer expectations, and reduced willingness to pay have resulted in a declining return on innovation investment (Ernst and Young 2017; PWC 2013).

In this context, open innovation might be a suitable approach for fostering innovation outcomes in the med tech industry. Open innovation refers to "the use of purposive inflows and outflows of knowledge to accelerate internal innovation, and expand the markets for external use of innovation, respectively" (Chesbrough 2006, p. 1). In essence, open innovation is an approach for opening traditionally closed innovation processes to external actors and thus making use of networks of actors when innovating products, services, and business models. In open innovation processes, seekers (firms looking for innovations in particular areas) and solvers (firms and individuals who possess innovation-related knowledge) interact to create solutions to innovation challenges. The main impetus for open innovation is that no enterprise 
possesses all the resources and knowledge that may drive its innovations. Potential benefits of acquiring and applying knowledge of external parties are discussed widely in literature and include, among others, gaining access to relevant resources, new markets, and speeding up development (Bogers et al. 2017, 2018; Dahlander and Gann 2010; Enkel et al. 2009; Huff et al. 2013).

One way to foster open innovation is to implement an open innovation or crowdsourcing platform (Adamczyk et al. 2012; Leimeister et al. 2009; Mazzola et al. 2018; Schlagwein and Bjørn-Andersen 2014). Such a platform can be defined as a virtual environment initiated by an organizer (e.g., a for-profit or non-profit organization) that enables the time- and locationindependent, voluntary interaction of innovation seekers and solvers to create innovation outcomes (Hallerstede 2013). These platforms are often operated by an intermediary as an electronic marketplace matching innovation supply and demand (Alt and Klein 2011; Holzmann et al. 2014; Möslein 2013). Moreover, they are multi-sided because they are characterized by cross-side network effects between heterogeneous participants (Holzmann et al. 2014; Tan et al. 2015). Most research focuses on previously established open innovation platforms provided by experienced operators (Hallerstede 2013; Schlagwein and Bjørn-Andersen 2014). There is a lack of knowledge concerning how such a platform may be established and which generally applicable design principles for establishing such a platform may be used.

For each participant in a multi-sided open innovation platform, the attractiveness of an open innovation effort is dependent upon the contributions from one or more additional participants aside from the platform operator. Systematic pursuit of open innovation involves much more than providing an open innovation platform or other technical artifacts. Open innovation involves collaboration between people who may not know each other at all and who may have little or no experience with open innovation. It is currently not obvious how specific instances of open innovation should unfold.

Our research occurred in the context of a med tech industry cluster, which is a geographic concentration of approximately 200 member firms and associated research institutions in the med tech field. These organizations connect with one another to share information and pursue other areas of mutual benefit, but may also simultaneously compete against one another (Porter 1998). The opportunities of open innovation are especially high for med tech clusters because many parties may have ideas and insights related to important medical innovation challenges even though they are not contractors or employees of a particular med tech firm who desire to pursue those challenges (Bullinger et al. 2012; Habicht et al. 2013; Lettl et al. 2006).

Despite the potential benefits, the med tech industry has been slow in adopting open innovation thus far. This industry tends to be closed rather than open because technological progress, advances in internal knowledge, and patents are often viewed as key factors in a firm's success and longterm survival (e.g., Prock 2017). One of the few examples of multi-sided open innovation platforms relating to med tech is Patient Innovation (www.patient-innovation.com), which was initiated to foster a global knowledge exchange among patients, medical specialists, and caregivers for mutual learning and improving the quality of patients' daily lives.

There is little or no current research covering how multisided open innovation platforms can be systematically established in industry clusters in which firms have no prior experience with this innovation approach. Although there is some history of research on applying open innovation in healthcare and med tech (e.g., Bullinger et al. 2012; Habicht et al. 2013; Lettl et al. 2006), none of the research we found addresses the issue of creating an open innovation platform. Based on the above information, this paper addresses the following question:

What problems may arise in the process of systematically establishing a multi-sided open innovation platform in a med tech industry cluster in situations where firms had no prior experience with this approach and how can these problems be overcome?

By answering this question and reflecting upon our findings, we aim to identify design principles that may support the establishment of multi-sided open innovation platforms in other contexts. In doing so, our goal is to develop constructive knowledge (Goldkuhl 2012) that contributes to both theory and practice (van de Ven 2007). This paper proceeds as follows: first, we summarize the theoretical basis of this research by explaining open innovation more thoroughly. We also describe work system theory (WST) as a means of structuring our analysis. Next, we follow an action research approach in which we collaborate with a German med tech industry cluster. Based on discussions with stakeholders, we create an initial view of how firms in the med tech cluster might engage in open innovation projects with the help of a multi-sided open innovation platform provided by the cluster management in collaboration with further participants. We qualitatively analyze the interactions of the different platform participants to determine problems that may arise in the process of establishing a multi-sided open innovation platform in a med tech industry in situations where firms had no prior experience with this approach and to identify how these problems may be overcome. In the discussion, we reflect on how the results of our action research approach could be bundled in general design principles to be used in similar settings. In doing so, we compare our findings with existing literature on platform design in the context of open innovation. 


\section{Theoretical foundations}

Two sources provide the theoretical foundations of our research: the concept of open innovation, and concepts from WST. The latter helped us structure our research process, which involves defining the initial work system of a multisided open innovation platform, observing it in operation, and pondering how to cope with the identified issues.

\section{Open innovation}

Open innovation is a broad concept that has been widely researched across various domains (Bogers et al. 2017). Open innovation has been discussed from two general perspectives: the emergent open innovation perspective, and the corporate open innovation perspective (Huff et al. 2013). The emergent open innovation perspective is largely inspired by the open source approach to software development. It describes the phenomenon of self-organized, self-motivated, and internet-based collaborative actors (Lakhani et al. 2006; von Hippel 2005). The corporate open innovation approach provides a more planned approach for acquiring knowledge and other resources in organizational settings (Bogers et al. 2018; Chesbrough 2003, 2006). Its focus is on the benefits of cooperating extensively with external stakeholders throughout product and service development (Alam and Perry 2002; Chesbrough 2003; Lee et al. 2010). In this context, the use of information systems is considered a critical catalyst for both product and service innovation (Nambisan 2013).

Open innovation can call for monetary exchange (pecuniary open innovation) or can be conducted without any monetary exchange (non-pecuniary open innovation). It can be viewed from the perspective of the seeker (inbound open innovation) or from the perspective of the solver (outbound open innovation). Those variables yield four perspectives on open innovation, as discussed in more detail in an extensive literature review by Dahlander and Gann (2010).

Inbound pecuniary open innovation refers to acquiring required knowledge for the development process. Cooperating closely with key partners in innovation networks can expand a firm's resource base significantly (Powell et al. 1996) and can leverage complementary competencies for development efforts (Dyer and Singh 1998).

Inbound non-pecuniary innovation addresses the free sourcing of knowledge from external stakeholders. For instance, Laursen and Salter (2006) found that searching widely and deeply across various external stakeholders, such as leadusers, suppliers, and universities can provide crucial input for sensing and seizing innovation opportunities. In this vein, firms can enhance the benefit of using stakeholders' knowledge by actively co-creating alongside them for innovation purposes and obtain direct access to the stakeholders' needs, understanding, and use of products and services (Schlagwein and Bjørn-Andersen 2014).

Outbound pecuniary open innovation is an attempt to commercialize internal resources outside a firm's boundaries (e.g., by out-licensing previously unused technologies) because an external partner may be more thoroughly equipped to introduce inventions to the market. Chesbrough and Rosenbloom (2002) found that path-breaking technologies developed within a research laboratory are often not aligned with the business model of the funding firm. Thus, out-licensing them to a venture with a substantially different business model may be in the interest of both corporations because it may unlock latent value of the technology.

Outbound non-pecuniary open innovation represents the disclosure of internal resources to the external environment without seeking immediate financial gains. Research about open source software has shown how this approach may foster cumulative advancements without any contractual basis (Henkel 2006; West and Gallagher 2006).

Our research pursues a combination of outbound and inbound pecuniary open innovation. The seekers (who are looking for ways to provide innovation to their customers) apply inbound pecuniary open innovation, while the solvers (who would like to receive compensation for solutions for the seekers) pursue outbound pecuniary open innovation. Our research focuses on connecting heterogeneous seekers and solvers conveniently and effectively via a multi-sided open innovation platform.

As defined in the introduction, open innovation platforms represent virtual environments that structure the transfer of innovation-related knowledge (Hallerstede 2013). They can be operated by an intermediary as an electronic marketplace that matches innovation supply and demand (Alt and Klein 2011; Holzmann et al. 2014; Möslein 2013).

In the context of these platforms, cross-side network effects exist because the value of platform membership increases for seekers with increasing numbers of solvers, and vice versa. Depending on the focus and objective of the platform, there are further participants aside from intermediaries, seekers, and solvers taking on various tasks. They can act as supporters of the innovation process (e.g., as innovation consultants), negotiate the transaction process (e.g., as legal and patent experts), or conduct the marketing of the platform and its challenges (e.g., as a cluster management). Thus, open innovation platforms are typically multi-sided and serve various entities with heterogeneous interests ( $\operatorname{Tan}$ et al. 2015).

Existing bodies of literature regarding platform-based open innovation have covered different topics, including activities to effectively match innovation and knowledge demand with supply (Brunswicker and Hutschek 2010; Gatzweiler et al. 2017; Randhawa et al. 2018). The design of the reward structure with monetary prizes and further incentives is an additional topic of interest (Antikainen 
et al. 2010; Boss et al. 2017; Ihl et al. 2018). Furthermore, research analyzed capabilities for motivating and supporting participants to contribute to open innovation (e.g., Brunswicker and Hutschek 2010; Randhawa et al. 2017,2018 ). Promotors of innovation communities (Fichter 2009) and the appreciation of participants and their work (Ebner et al. 2009; Hofstetter et al. 2018; Natalicchio et al. 2014) have also received attention. Another widely explored issue is the transfer of innovation demands into appropriate challenge design (Hossain 2018; Lichtenthaler and Ernst 2008; Martinez and Walton 2014). Gatzweiler et al. (2017) have examined deviant behavior and its consequences in the context of open innovation platforms. As it becomes obvious, scholars have primarily investigated individual subject areas relevant for establishing open innovation platforms. Thus far, constructive knowledge fostering an integrated understanding for general practice is missing.

\section{WST-based system analysis}

Our research produced an open innovation approach that harnessed a multi-sided platform on which seekers in the med tech industry find and engage solvers who provide solutions to innovation challenges. A full description of those activitiesalong with the related context and results - involves much more than just using a web-based platform. For conceptualizing and implementing our open innovation initiative, we utilized WST as an analytical lens (Alter 2013, 2015). According to WST, a work system is conceptualized as "a system in which human participants and/or machines perform work (processes and activities) using information, technology, and other resources to produce products/services for specific internal and/or external customers" (Alter 2015, p. 488).

A work system is a general case for thinking about systems within or across organizations. The work system method starts with the identification of the smallest work system that exhibits a problem or opportunity that launched the analysis. After current performance gaps are clarified, the work system is summarized on a single page in the form of a work system snapshot comprising six central elements of the work system framework. More specifically, the snapshot depicts the work system on a one-page, text-based summary of six elements: (1) the customers, (2) the products/services produced, and (3) the main processes and activities of the work system under consideration. Moreover, it details (4) the participants, (5) technology, and (6) information required for executing these processes and activities (Alter 2013). Analysts (designers) explore situation-specific issues at whatever level of depth is appropriate for the purpose at hand. Then, they propose changes that will improve the work system and explain why those changes should generate more favorable performance (Alter 2013).

\section{Action research at a German cluster of excellence in the med tech industry}

This section starts by explaining the background that launched our action research effort. Next, it explains how the open innovation approach and the related multi-sided platform may be viewed as a work system. The next section will look at the data collection and data analysis in more detail.

\section{Background related to an excellence cluster in med tech}

This study was a collaborative effort involving our research team, the management of Medical Valley EMN (www.medical-valleyemn.de), a German cluster of excellence in med tech, and a commercial open innovation technology provider called innosabi, a leading German company in this field that focuses on software for agile innovation (www.innosabi.com). Medical Valley EMN was established in 2007, and by the year 2018, it had almost 200 organizational members (the majority including small- and medium-sized med tech firms). The cluster region includes approximately another 300 firms, 80 university institutes, and 20 independent research organizations with a focus on med tech or related topics. While many cluster firms are renowned world market leaders in specific medical technologies, they often lack competences in areas that are essential for developing future products and services. When our research began in 2014 , the potential for networking and synergizing between organizations within the region was barely utilized and had little positive impact on the cluster's overall innovativeness. The research consortium decided to pursue those potential benefits by developing an effective multi-sided platform solution for promoting the application of open innovation within the cluster. In doing so, the goal was to reach out for a multitude of solvers who were not necessarily linked to the cluster or medical technologies and to inspire innovation activities. The regional concentration simplified access to data and enabled us to build trustful relationships allowing for in-depth insights. Concretely, four open innovation challenges were announced in 2014 and were solved over a period of four months.

\section{Description of the action research process}

This study follows the action research method (Baskerville and Myers 2004; Hult and Lennung 1980; Susman and Evered 1978). According to Hult and Lennung (1980), "action research simultaneously assists in practical problem-solving and expands scientific knowledge, as well as enhances the competencies of the respective actors, being performed collaboratively in an immediate situation using data feedback in a cyclical process aiming at an increased understanding of a given social situation" (p. 247). 
Action research can be considered a particular form of engaged scholarship (van de Ven 2007), as the researcher works collaboratively with other relevant stakeholders to bring about change in a real-world situation (Checkland 1991; Mathiassen et al. 2012). Being rooted in the paradigm of pragmatism, the goal of action research is to develop constructive knowledge that is considered useful in general practice (Baskerville and Myers 2004; Goldkuhl 2012). Relying on change through action and learning through reflection (Davison et al. 2004), this research approach has been considered "ideally suited to the study of technology in its human context" (Baskerville and WoodHarper 1996, p. 235). It has previously been successfully applied for the development of design principles in the context of information systems (e.g., Kohler et al. 2011; Lindgren et al. 2013), and thus was considered appropriate for this study.

For this study, we follow Susman and Evered's (1978) action research process, which has been adopted in information systems research (Davison et al. 2004; Lindgren et al. 2013). Throughout this process, two of the authors directly engaged with practitioners to conceptualize the multi-sided open innovation platform, selecting appropriate challenges and helping spread them among potential participants. They were also involved in consulting activities concerning legal affairs, requirements analyses, and the creation of evaluation criteria for submissions to the challenges. Moreover, together with two other authors, they were responsible for the theoretical grounding of this research as well as the execution of data collection and analysis. One more author helped structure the findings and arguments, but did not have an active role in the project. The authors worked together with the practitioners in the context of a publicly funded research project. None of the authors were employed by an industry partner of this action research study, nor were any authors paid for submitting solutions to the platform. The different phases of the conducted action research study are described in greater detail in the following subsections.

\section{Diagnosing phase}

The diagnosis of the situation started with discussions with the med tech cluster's management team, where project members were introduced to the current issues and resource constraints concerning open innovation as well as its future objectives. Improving the innovativeness of cluster members was viewed as a critical success factor for remaining at the forefront of med tech excellence, and management regarded this project as strategically important.

Project start-up included insights from literature on the application of open innovation and 30 semi-structured interviews (about $10 \mathrm{~min}$ ) were conducted with decision makers of randomly selected firms within the cluster. The main goal of these brief interviews was to more thoroughly understand the heterogeneous demands and barriers for the application of possible organizational partners in order to assess the prospects of the envisaged approach's success.

\section{Action planning phase}

During this phase, we collaboratively decided how to pursue our action research project in detail and established a road map for the next months. Building on the literature introduced above and the practical experience of the technology provider, we started by imagining how a multi-sided open innovation platform might operate. We conceived of an open innovation work system that would use the platform, and we summarized the work system using a work system snapshot (see Table 1). We intended to apply this general approach to some specific cases to observe the platform in operation and reflect on certain aspects of the work system, including the processes, platform, information, and so on.

Thinking of the open innovation initiative as a work system aimed to move the emphasis away from the applied web-based platform technology and redirect it toward a more businessoriented view of how the larger sociotechnical system might operate. Figure 1 illustrates the participants involved in that work system and realizes the multi-sided open innovation platform and their motives for participation in the action research study: innovation seekers, potential innovation solvers, the cluster management as an official service provider, innovation consultants, and legal advisors. Whereas seekers and solvers were self-selected by advertising the project in the cluster, the other participants were selected in accordance with the cluster management of Medical Valley EMN as part of the overall project team. In this context, the technology provider was innosabi. Together with two of this study's authors, representatives of innosabi also worked as innovation consultants.

Table 1 shows different types of information that would be relevant to the platform operation. The processes and activities would include a variety of steps performed by seekers, solvers, and other participants. After establishing the initial concept of the open innovation work system, as shown in Table 1, we identified three very diverse organizations that faced four specific innovation challenges relative to med tech. A final part of the action planning phase was the creation of the web-based open innovation platform itself, which would be used in the four open innovation projects. The platform was based on an existing product of the technology provider who was responsible for its technical operation and performed the coding. The authors were closely involved in conceptual aspects of the design, thereby ensuring that insights from the diagnosing stage were considered.

\section{Action taking phase}

Once the platform was implemented and the service was launched, the researchers observed and supported the 
Table 1 Snapshot of the open innovation work system as initially implemented

\begin{tabular}{|l|ll|}
\hline \multicolumn{1}{|c|}{ Customer } & \multicolumn{1}{c|}{ Services } \\
\hline Seekers & $\bullet \begin{array}{l}\text { Potential matches between seekers and solvers } \\
\end{array}$ & $\bullet \begin{array}{l}\text { Negotiated agreements between seekers and solvers } \\
\text { Innovative ideas for seekers }\end{array}$ \\
\hline \multicolumn{2}{|c|}{ Major activities and processes } \\
\hline Registration
\end{tabular}

- Seeker learns about the open innovation platform via standardized information material, either electronically or in person

- Solvers receive information about the open innovation platform via events, e-mailing, website/blog visits, information events, personal discussions, print materials, etc.

- $\quad$ Solvers visit website, agree to terms of use, and register

Project setup

- $\quad$ Seeker contacts the cluster management and signs project agreement

- Seeker interacts with innovation consultant to formulate project agreements (i.e., innovation challenge, award, evaluation criteria, and timeframe of contest) OR seeker formulates project agreements independently, supported by downloadable PDF manual

- Legal advisor checks the project agreement

- The cluster management officially launches specific open innovation challenge

Open innovation process

- Automated newsletters inform registered solvers about the current innovation challenge

- Solvers identify project fitting to their competences

- Solvers use discussion section of the platform to point out any uncertainties concerning the challenge

- Seekers directly answer any specific questions

- After accepting project agreements, solvers upload their solutions

- Innovation consultant supports seekers in choosing winners

- Transfer of right of disposition and use from solver to seeker

- Transfer of prize money from seeker to solver (cluster management as intermediary)

- Solvers are informed of winning solutions and end of contest

\begin{tabular}{|c|c|c|}
\hline Participants & Information & Technologies \\
\hline $\begin{array}{ll}\text { - } & \text { Seekers } \\
\text { - } & \text { Solvers } \\
\text { - } & \text { Cluster management } \\
\text { - } & \text { Legal advisor } \\
\text { - } & \text { Technology provider }\end{array}$ & $\begin{array}{ll}\text { - } & \text { Advertisement for seekers } \\
\text { - } & \text { Advertisement for solvers } \\
\text { - } & \text { Specific open innovation project } \\
\text { - } & \text { agreement } \\
\text { - } & \text { Discullenge information } \\
\text { - } & \text { Information about solution and } \\
& \text { winners }\end{array}$ & $\begin{array}{l}\text { - } \quad \text { Web-based open innovation platform } \\
\text { - } \quad \text { Web-based newsletter application } \\
\text { - }\end{array}$ \\
\hline
\end{tabular}

process by which seekers defined and advertised innovation needs; solvers learned about those needs and proposed solutions accordingly.

At this stage, the envisaged procedure of the open innovation projects occurred as follows. The seeker recognized an innovation need and described it as an innovation challenge. The innovation challenge was expressed as a stated problem including many details and requirements needed to understand the problem. This step should either be conducted by the seekers themselves or along with the support of an innovation consultant provided by the cluster management. The innovation consultant should be a professional expert in the field of open innovation who guides the seeker through the entire process of using the platform. Next, the challenge was listed on the open innovation platform for a specified period of time. The heterogeneous solver community engaged in the challenge after being informed by the cluster management via press releases and e-mail campaigns. The seekers analyzed and evaluated all solutions submitted 


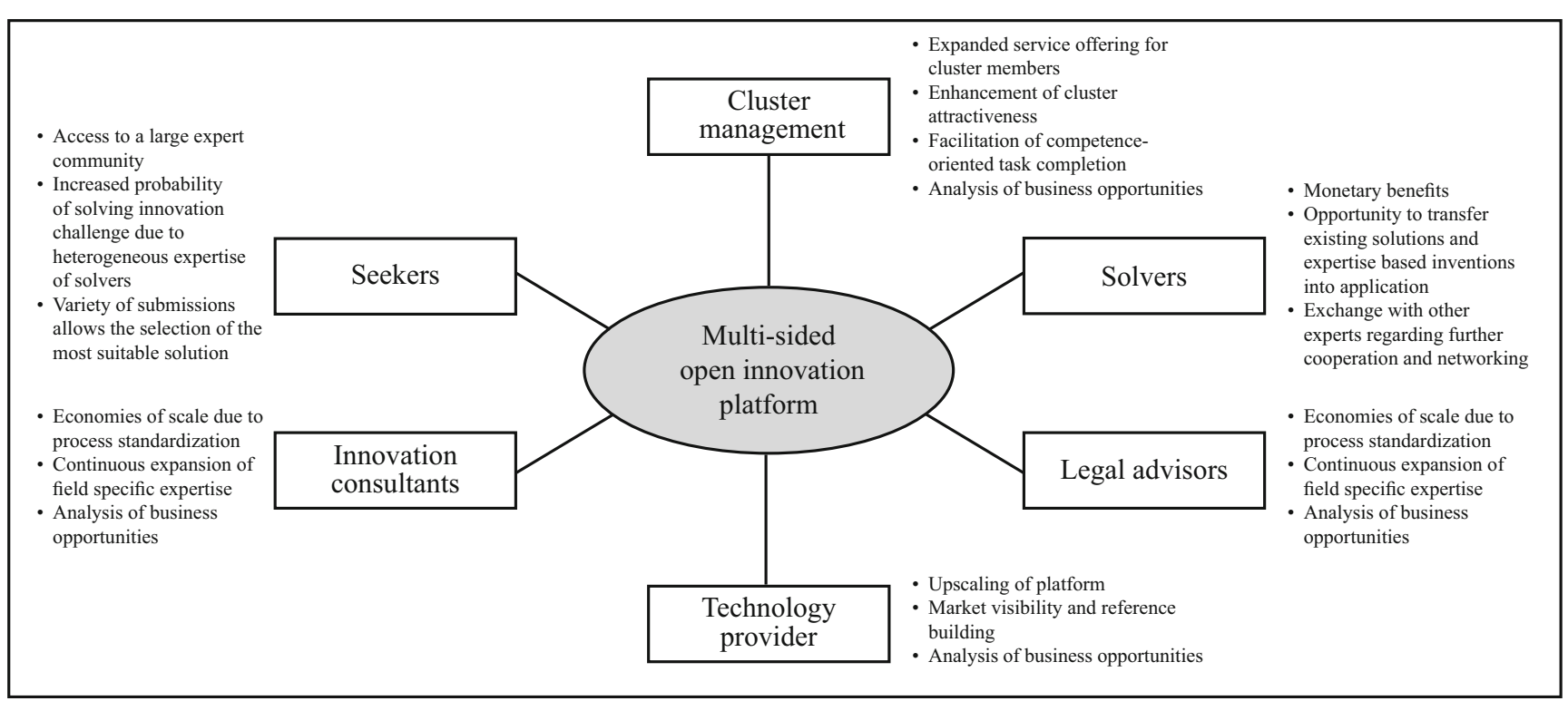

Fig. 1 Motives of different groups of participants contributing to our research project

within the prescribed time limit and with support from the innovation consultants. Only solutions that met all requirements were considered. The best feasible solution won the contest and the solver received the prize money in exchange for the legal right to use the solution. This entire process was monitored and supervised by the cluster management.

Throughout the action research process, four innovation challenges were broadcasted via the website:

- Optimizing radiology processes: attaining maximum efficiency for both patient and doctor in patient examinations that utilize imaging. The solution should provide a new, efficient system to optimize the processes for patient examinations with imaging procedures. A uniform standalone, in-house IT-solution should support this process.

- Pattern projector: generating a (pseudo-)random, nonrepetitive monochromatic light-pattern in a defined field of view. The solution should provide a concept for a new pattern projector for computer vision tasks in medicine.

- New applications for 3D cameras: finding new applications for real-time 3D range imaging cameras (e.g., Kinect, Time-of-Flight) in medical applications and related fields. The solution should provide possible areas of application of 3D real-time cameras that are inspired by the usage of those cameras in the healthcare sector.

- Promoting a medical platform: defining how a novel platform for personalized medicine for children can be successfully launched and marketed. The solution should provide an innovative concept to launch and market a platform that focuses on personalized medication for children.

All in all, a total of 34 solutions to all four challenges were submitted.

\section{Evaluation phase}

The evaluation phase studied interactions and results using the multi-sided open innovation platform. The research team reviewed all documentation and observations (i.e., statistics and log-files of platform activities, questions, responses in the platform's discussion section, and notes from project meetings) and conducted in-depth interviews with the responsible decision makers of the cluster management and three industrial partners who were seekers in the trial implementation of the platform. Moreover, ten solvers were chosen to share their experiences with the platform. For this, we conducted theoretical sampling (Glaser and Strauss 1967), as we aimed to talk to both successful and unsuccessful solvers who contributed to the various challenges. Ten of these thirteen interviews were conducted face-to-face, while three were conducted via telephone. All interviews followed semi-structured guidelines and lasted between $30 \mathrm{~min}$ and $60 \mathrm{~min}$. Additionally, we conducted six telephone interviews with decision makers of potential seekers in order to gain insights concerning their perceptions of the service and to identify unmet needs. These interviews lasted approx. fifteen minutes, all of which were recorded and later transcribed.

We distributed separate online surveys to seekers and solvers that complemented the qualitative analysis. The questionnaire was developed to gain a deeper understanding of the requirements of an open innovation work system for the cluster. First, the survey asked seekers and solvers about their familiarity with open innovation as well as motives and barriers for participating in open innovation initiatives. The survey included questions concerning operational aspects of the platform. Some questions addressed seekers' and solvers' preferences for data privacy and communication channels. Other questions addressed 
demographic issues. All in all, we received usable responses from 50 (potential) seekers and 150 (potential) solvers.

In addition, the results of an expert workshop were analyzed. The workshop was organized in the context of the International Symposium on Open Collaboration, held in August 2014 in Berlin. Challenges we encountered that were relative to portraying open innovation opportunities on the platform were presented to an audience of scholars from the field of information systems through a $15-\mathrm{min}$ presentation, followed by a 30-min open discussion covering how to approach such challenges. The summary of the open discussion was recorded and later transcribed.

The goal of our analysis was to generate knowledge related to the research question regarding which problems may arise in the process of establishing a multi-sided open innovation platform in a med tech industry cluster in situations where firms had no prior experience with this approach and how might these problems be overcome. For analyzing transcripts and documentations, a template analysis was conducted (King 2004) using the qualitative data analysis software MAXQDA11. Based on the six parts of the work system snapshot, the first set of categories was implemented. Afterward, new codes were developed inductively, resulting in a set of 310 first order codes. Next, the first order codes were reevaluated with the goal of finding exhaustive and mutually exclusive categories (Krippendorff 2013). This second assessment led to the renaming and consolidating several first order codes, creating 43 second order codes. Coding was independently conducted by two of the authors. In doing so, justifications for revisions were presented and the definitions for the utilization of codes were generated (King 2004). The results were compared until a satisfactory level of agreement was realized concerning the evolving template. Following this structure, each category of the work system was jointly discussed to identify the main problems and opportunities related to the operation of the open innovation system. In order to analyze the online survey, response data was exported into a spread sheet and the most significant insights were transferred into a textual description that was subsequently shared and discussed with all project partners for analytical purposes. The results of our analysis were depicted in a "to-be" work system snapshot. In the following section, the results, problems, and opportunities identified throughout the four open innovation projects are presented.

\section{Results}

This section initially presents the outcomes of the open innovation work system instantiated throughout the action research process. Afterward, it depicts the main problems we encountered throughout this process and presents the envisaged opportunities for improvement.

\section{Outcomes of the instantiation of the initial open innovation work system}

Throughout the pilot stage of four months, the multi-sided open innovation platform achieved its goal; all four innovation challenges were solved. Most solvers originated from Germany and were young professionals in the fields of engineering, business, and medicine. However, one winning solution was created by a team from Turkey, who demonstrated that the service also enables seekers to benefit from international expertise. To summarize, 205 solvers registered on the website and produced 34 proposals for solving the broadcasted challenges. Each week, an average of 140 people visited the platform. The seekers were satisfied with the quality of the submissions, as demonstrated by the quotes of the CEOs of these organizations:

"At the beginning we were skeptical if a very specific, technical question can be solved with the help of this service. However, we are very enthusiastic about the winning solution" (Se-M-01).

"Within a very short time, we could gather interesting and creative concepts to foster the market launch of our new product. In the next stage, we will implement the best ideas" (Se-M-02).

"The winning solution is particularly interesting as it discusses the influence of current megatrends on radiology practices in detail. We will utilize the presented ideas to make our member organizations fit for the future" (Se-M-03).

The management team of the cluster association was also satisfied with the results. Analyzing the results of a wellknown, commercial open innovation marketplace, Lakhani et al. (2006) found that approximately $30 \%$ of scientific challenges could be solved. Thus, solving all challenges throughout the trial phase of the platform may be regarded as an indicator that the ideas built into the open innovation work system have the potential to improve the cluster's innovativeness on a larger scale. In this regard, the cluster management stressed:

"In the next years [we] want to continue the current path and establish more international innovation partnerships. In the future, [we] will increasingly conduct ideation and open innovation-projects at the interface between medical technology and other industries" (Published Brochure of Cluster Management).

\section{Main problems and opportunities}

Based on the evaluation activities described above, we inductively identified several interrelated problems (P) and 
opportunities $(\mathrm{O})$ for establishing a multi-sided open innovation platform as part of a larger work system. Problems and opportunities were relevant to all four challenges investigated. In the following subsections, these aspects are described according to their overarching themes.

Understanding the open innovation work system Interested seekers were primarily small- and medium-sized enterprises that operated in very specific areas within the med tech industry, such as 3D visioning, orthopedic solutions, or diagnosis technology development. While most of these enterprises regularly collaborate with external actors throughout innovation processes, none of them had ever previously participated in a dedicated open innovation work system. To educate potential seekers on the new platform, we distributed an extensive set of standardized information. However, standardized information was not well-suited to the individual questions and needs of seekers or solvers (P1). Moreover, we found that, despite being very interested in participating, many firms found it difficult to identify and articulate internal innovation challenges that might be addressed by the open innovation approach (P2):

"To the best of my knowledge, the decision against par-
ticipating in the project was because we were not able to
identify any questions suited for the open innovation
platform. Neither within the research nor the product
development department...But we are interested in the
concept and I am positive, if there are more time and
support, we will identify some questions" (PoSe-F-01).

In this context, we found that personal exchange between the prospective seekers or solvers and the innovation platform provider was important for learning to generate interest in the overall approach, clarify its potential and limitations, and identify suitable innovation challenges (O1). Offline events, such as the cluster summit, seemed to be important factors for diffusing related information both within the cluster and personally to top-level decision makers of potential seekers. We found that such personal encounters were of utmost importance for building momentum and enthusiasm for the possibility of distributed problem-solving:

"I am convinced of the concept; this is also why I am so enthusiastic and keen about our conversation. I am confident that this approach combined with brainstorming and the combination of different disciplines enables to solve unanswered questions more effectively" (PoSe-F-02).

Decision makers who were convinced about the possibilities were willing to promote the multi-sided open innovation platform within their own organizations and help overcome any internal barriers $(\mathrm{O} 2)$. We concluded that an improved approach should include introducing the open innovation concept personally in a face-to-face setting and jointly identifying suitable innovation challenges.

Responsibilities of participants Participants' expectations concerning their role and related responsibilities throughout the open innovation process varied greatly across the four cases. In this context, the basic service contract the seekers signed did not explain their rights and responsibilities in sufficient detail (P3). Optimizing the effectiveness of the open innovation system requires greater clarity regarding necessary seekers' responsibilities and their enforcement $(\mathrm{O} 3)$. Seekers must recognize their integral role on the platform, namely since their continuous feedback is mandatory in later stages of the innovation process (e.g., for answering solvers' specific questions arising throughout concept development). Seekers have to assess the fit between their needs and a proposed solution. Related feedback should be provided swiftly because concept development may be on hold until specific questions are answered:

"Yes, moreover, feedback from the seeker would have
been necessary...I kept on posting questions but [these]
were answered irregularly. Here, I wished for faster
feedback especially because we solvers work on the so-
lutions during our spare time. If I sit down and start
working on the project and there occurs a question
which can only be answered by the seeker, then I expect
feedback in the next 24 to 48 hours and not in a period
of the next two weeks" (So-M-01).
"Yes, I would not have asked for frequent feedback but
for certain points in time for which I could expect feed-
back. This was unfortunately not the case" (So-M-03).

To improve seekers' cooperation in the future, seekers' rights and responsibilities must be specified in greater detail and seekers should designate a responsible open innovation project manager who is committed to directly engaging with solvers and promptly providing feedback. Additionally, automated notifications should be implemented by the technology provider to assure that seekers are always aware of any queries concerning their challenge and to inform solvers when their request is answered.

On the other hand, solvers must understand submission criteria related to each challenge. In some cases, solvers seemed to ignore these criteria deliberately and tried to engage in a challenge when they had no expertise regarding a specific requirement $(\mathrm{P} 4)$ :

"Especially...it cannot be expected that the participants are familiar with all aspects of medical engineering and law if their profession is not in this area. This is why I did not consider this [criterion] since it is not within my expertise" (So-M-03). 
Solvers must understand that submissions not adhering to the submission criteria will be rejected even if their ideas are promising. A reminder of all submission criteria should be included and must be checked before unlocking the platform's submission function. Moreover, solvers should be automatically notified to check for a confirmation stating they have successfully uploaded their solution.

Benefits of participation All interviewed solvers expected various benefits from their participation, such as monetary prizes, learning, or career options. In this regard, it was criticized that monetary prizes were only awarded to the best three submissions selected by the seeker, while other motives were not addressed (P5). For instance, solvers consistently stressed that they expected detailed feedback for their work. In doing so, the seeker would demonstrate appreciation for solvers' efforts and solvers could access experts' knowledge:

"For me, it is very important to get decent feedback afterward. If I don't receive it...then I will not participate again. But if I get feedback and see that the seeker seriously reviewed my work...then I am open for future participation" (So-M-04).

In order to address the expected heterogeneous benefits and demonstrate appreciation for solvers' efforts, it was determined critical that solvers include non-monetary rewards for future instantiations of the multi-sided open innovation platform (O4). For example, several solvers - predominately those who were young professionals or graduate students - highlighted that they aimed to enhance their career options and possibilities with the goal of improving their reputation:

\section{"One thing is to get in contact with companies for the time after my work here at the chair. Yes, that is really interesting to me. To demonstrate what I am capable of" (So-M-06). \\ "I want some kind of reward and, moreover, to improve my competitiveness in the field of projects, the job mar- ket, and future assignments. Everything which improves my own reputation is welcome in this context" (So-M- 04).}

In order to address these expectations, among others, the technology provider may implement game design elements such as redeemable points for qualified contributions (e.g., answering questions on the website's discussion board). This would not only improve solvers' reputations, but could also be traded in for participation in events organized by the cluster management, professional training, or certificates.

Challenge-related communication In all four trial cases, ensuring that participants only received relevant information throughout the open innovation process proved to be problematic (P6). Solvers stressed that they preferred individualized communication regarding new challenges in accordance with their interests and skills (O5). In this regard, most solvers stated that they wished to be informed by the cluster management about new challenges via topic-specific newsletters:
"Well, if it is the point to inform someone about this, I would prefer a newsletter. But the newsletter should not be sent out too often, but rather contain a bunch of useful information at one time...If there was the option to select certain topics someone wants to be informed about, I would choose this...In general, if I do not receive a newsletter too often, but maybe every first or second month, then it will work out. Otherwise, I would unsubscribe" (So-M-05).

Additionally, in the online survey, approximately $30 \%$ of potential solvers claimed that, in the future, they would like to be informed about new challenges via social media channels. Thus, the cluster management should integrate a dedicated social media approach into the next development stage of the open innovation work system. Finally, we found that the media-enriched presentation of particular challenges is critical, as it enables the efficient conveyance of complex information (O6). If possible, short explanatory videos should complement written information to foster understanding. Moreover, a short introduction video by the seeker can demonstrate the importance of their challenges, which may exert a positive influence on solvers' motivation:

"Video seems to be a good idea because it is a different form of presentation which can bring a certain picture or sentence more efficient to someone's mind than just reading a text. Thus, a video explaining the platform in general or, like said, each competition, a short wrap up, that would be good" (So-M-05).

\section{A revised view of how the open innovation work system should operate}

The analysis of the four challenges demonstrated the need for a revised view of how multi-sided open innovation might operate in the specific med tech industry cluster being considered. Table 2 is a work system snapshot that updates our initial view presented in Table 1 based on the problems and opportunities identified above. Table 2 splits the processes and activities section of the work system snapshot into three sections: seeker's processes, solver's processes, and background processes. The reason for splitting sections this way is that it is easier to visualize separate processes performed by seekers, 
Table 2 Snapshot of the revised open innovation work system

\begin{tabular}{|c|c|c|c|}
\hline \multicolumn{2}{|c|}{ Customer } & \multicolumn{2}{|r|}{ Services } \\
\hline \multicolumn{2}{|l|}{ - $\quad$ Seekers } & \multicolumn{2}{|c|}{$\begin{array}{ll}\text { - } & \text { Potential matches between seekers and solvers } \\
\text { - } & \text { Negotiated agreements between seekers and solvers } \\
\text { - } & \text { Innovative ideas for seekers } \\
\text { - } & \text { Compensations for solvers }\end{array}$} \\
\hline \multicolumn{4}{|c|}{ Major activities and processes } \\
\hline \multicolumn{2}{|c|}{ Seeker activities and processes } & \multicolumn{2}{|c|}{ Solver activities and processes } \\
\hline \multicolumn{2}{|c|}{$\begin{array}{l}\text { - } \begin{array}{l}\text { Seekers are informed via standardized information } \\
\text { material and continuous events } \\
\text { New seekers engage in personal discussion with } \\
\text { innovation consultant to learn about the concept of open } \\
\text { innovation and receive support in identifying suitable } \\
\text { challenges } \\
\text { Experienced seekers contact cluster management directly } \\
\text { and may propose challenges independently } \\
\text { Seekers sign project agreement and designate a } \\
\text { responsible open innovation project manager } \\
\text { Innovation consultant supports formulating project } \\
\text { agreements (i.e., innovation challenge, award, evaluation } \\
\text { criteria, and timeframe of contest) OR seeker formulates } \\
\text { project agreements on his own, supported by } \\
\text { downloadable PDF manual } \\
\text { A short introduction video is taken either with the seeker } \\
\text { organization or with a representative of the cluster } \\
\text { management } \\
\text { Check-up of specific project agreements by legal advisor } \\
\text { Cluster management officially launches specific open } \\
\text { innovation challenge } \\
\frac{\text { Seekers are automatically informed via push notifications }}{\text { about solvers' questions }} \\
\text { - Seeker directly answers any specific questions } \\
\text { Innovation consultant supports seekers in choosing } \\
\text { winners } \\
\text { Transfer of prize money from seeker to solver (cluster } \\
\text { management as intermediary) }\end{array} \\
\text { - }\end{array}$} & \multicolumn{2}{|c|}{ 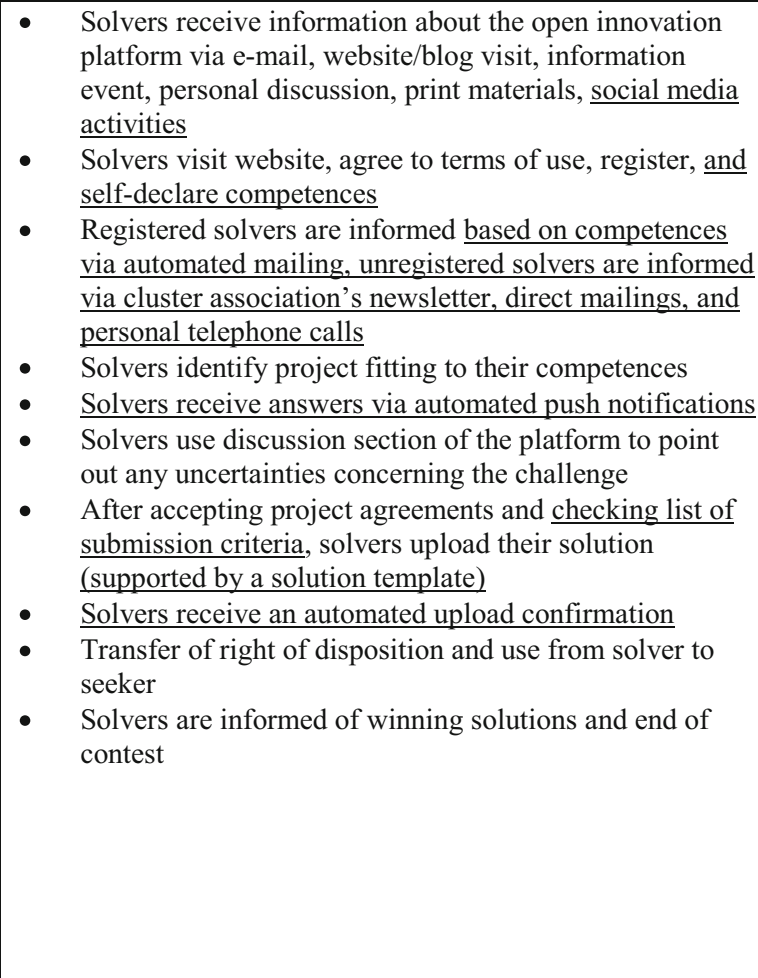 } \\
\hline \multicolumn{4}{|c|}{ Background activities and processes } \\
\hline \multicolumn{4}{|c|}{$\begin{array}{ll}\text { - } & \text { Cluster management engages in continuous community building } \\
\text { - } & \text { Cluster management controls transactions and settles any possible disputes } \\
\text { - } & \text { Cluster management continuously manages public relations and social media channels } \\
\text { - } & \frac{\text { Cluster management conducts financial management (e.g., payment of external service providers) }}{\text { Cluster management plans and manages social media campaigns }} \\
\text { - } & \frac{\text { Technology provider ensures platform maintenance }}{\text { Technology provider ensures data management and privacy }} \\
\text { - } & \text { Solvers automatically receive bonus points for qualified contributions via the web-platform }\end{array}$} \\
\hline Participants & \multicolumn{2}{|c|}{ Information } & Technologies \\
\hline $\begin{array}{ll}- & \text { Seekers } \\
\text { - } & \text { Solvers } \\
\text { - } & \text { Cluster management } \\
\text { - } & \text { Innovation consultants } \\
\text { - } & \text { Legal advisor } \\
\text { - } & \text { Technology provider }\end{array}$ & \multicolumn{2}{|c|}{$\begin{array}{ll} & \text { Advertisement for seekers } \\
\text { - } & \text { Advertisement for solvers } \\
\text { - } & \text { Serms of use } \\
& \text { agreement } \\
\text { - } & \text { Challenge information } \\
\text { - } & \text { Discussions on platform } \\
\text { Information about solution and } \\
\text { winners }\end{array}$} & $\begin{array}{ll}\text { - } & \text { Web-based open innovation } \\
\text { - } & \text { Wlatform } \\
\text { - } & \text { Social media } \\
\text { PCs, internet, email, and telephone }\end{array}$ \\
\hline
\end{tabular}


solvers, and other organizations who perform background work. Table 2 underlines the new content that was not mentioned in Table 1 in order to clarify the suggested changes. Most suggested changes for seekers and solvers focused on the clarity and convenience of communication. The issues motivating the suggested changes became apparent, as the project unfolded from our interviews and survey responses. Table 2 also mentions a series of background processes performed by cluster management or the technology provider. None of these processes were mentioned in Table 1, but many of them proved to be important during the four trial applications. When open innovation projects occur outside the context of a formal technology cluster, failure to deal with the related issues is likely to prove an obstacle to success.

\section{Discussion}

Following an action research approach, we explored what problems may arise in the process of systematically establishing a multi-sided open innovation platform in a med tech industry cluster in situations where firms had no prior experience with this approach and identified how these problems may be overcome. Using WST as an analytical lens, we conceptualized and implemented a multi-sided open innovation platform that was trialed in four successful open innovation challenges. We identified a range of problems and opportunities for overcoming them, leading to a revised view of how the open innovation work system might operate more effectively in the future. This section discusses our findings and represents the learning phase of the action research cycle (Susman and Evered 1978). Reflecting on our findings, we firstly derive design principles that may support the establishment of multi-sided open innovation platforms used in contexts where firms lack experience concerning open innovation. We secondly reflect on the use of WST as an analytical lens for conceptualizing and implementing our open innovation initiative.

\section{Derivation of design principles}

The design principles were developed inductively and were later compared with related literature on open innovation management and platform design. We propose that considering these principles can help overcome similar issues and harness opportunities as encountered in our action research study. Figure 2 depicts these principles as well as the particular problems and opportunities that inspired their conceptualization. Figure 3 presents related theoretical insights. The description of the design principles follows Chandra et al. (2015), who argue that design principles should be both action- and materiality-oriented. Thus, descriptions should encompass both "what an artifact should enable users to do" and "how it should be built in order to do so" (Chandra et al. 2015, p. 4043). Furthermore, relevant boundary conditions must be considered (Chandra et al. 2015).

The first design principle is coined "collaborative onboarding". This principle addresses the need that participants, particularly those with no prior experience with open innovation, must be supported in order to learn about the potentialities and requirements of utilizing the multi-sided open innovation platform. For this purpose, processes and means for sharing related knowledge and collaborative challenge planning should be implemented. Boundary conditions include platform management's experience, an in-depth understanding of participants' current knowledge, and the existence of trustful relationships between the various parties involved. The principle is in line with existing findings that highlight the need for encompassing knowledge transfer regarding open innovation (Gatzweiler et al. 2017) and simultaneously integrate participants already in the early stages of the innovation process (Ebner et al. 2009). In this regard, face-to-face interactions play a critical role (Brunswicker and Hutschek 2010) even if key interactions are executed in the virtual environment of a multi-sided open innovation platform (Randhawa et al. 2018).

The second design principle, "enforcing responsibilities", stresses the vitality of establishing a reliable division of labor among unexperienced participants according to their particular roles for realizing open innovation. For ensuring these actions, we propose that open innovation work systems should include clear contractual arrangements and supportive personnel, such as responsible project managers. Moreover, encompassing automated information exchange and coordination throughout the overall innovation process should be considered. This principle is dependent upon the commitment of the various participants as well as the possibilities of sanctioning non-compliant behavior. Against this backdrop, existing literature emphasizes the role of professional platform management (Gatzweiler et al. 2017; Natalicchio et al. 2014), including individualized support throughout the open innovation process (Brunswicker and Hutschek 2010; Randhawa et al. 2017, 2018) and monitoring compliance (Gatzweiler et al. 2017). Moreover, with respect to the responsibilities of seekers, it was found that short reaction time, especially in the case of complaints and dissatisfaction, is important (Gatzweiler et al. 2017).

The third design principle, "demonstrating appreciation", proposes that platform management should clearly express that unexperienced seekers must overcome an exclusive focus on monetary incentives and take into consideration other motives, such as self-marketing and learning. For this purpose, we propose that the open innovation work system should include processes for collaboratively designing suitable monetary and non-monetary rewards and ensuring appropriate feedback for contributions. Moreover, game design elements may 


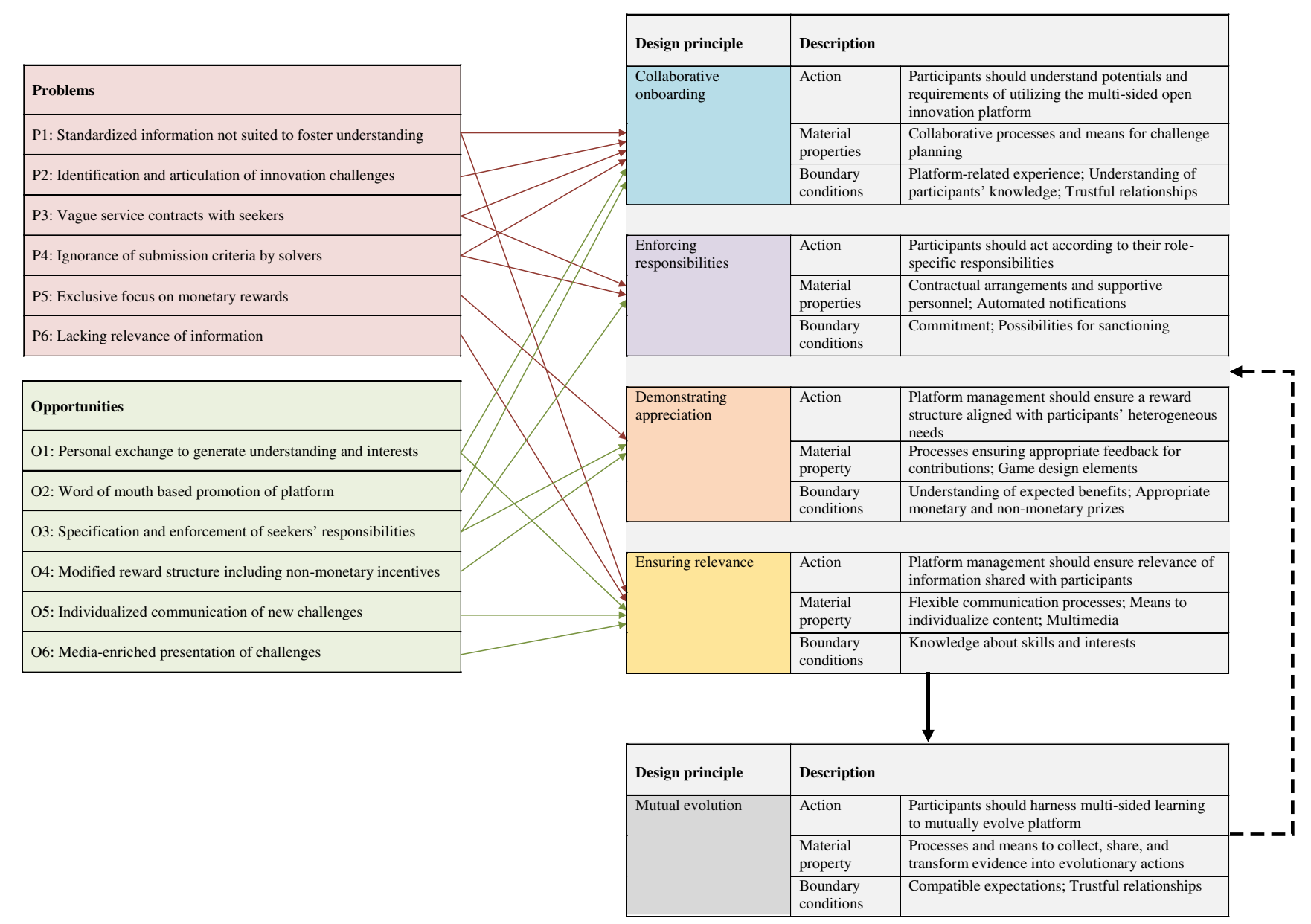

Fig. 2 Design principles derived from identified problems and opportunities

be applied, such as elements for visualizing achievements and thus enhancing solvers' reputations. In this context, it is fundamental that reward design builds on an in-depth understanding of solvers' expected benefits and seekers' abilities to fulfill them. The importance of non-monetary rewards has been extensively discussed in the literature (e.g., Antikainen et al. 2010; Ihl et al. 2018; Li and $\mathrm{Hu}$ 2017). For example, Natalicchio et al. (2014) propose that addressing solvers' intrinsic motivations in addition to monetary awards allows an increase in participation and the average quality of contributions. Furthermore, detailed and prompt feedback is considered critical (Ebner et al. 2009; Gatzweiler et al. 2017; Hofstetter et al. 2018).

"Ensuring relevance", the fourth design principle, stresses that platform management should focus on the appropriate and comprehensible transfer of information between participants of the open innovation work system. In this regard, we observed that inexperienced participants repeatedly lacked related understanding or competence. Thus, the open innovation work system requires flexible communication processes and technological means to individualize information content. Furthermore, multimedia can enrich the presentation of relevant information. In this context, as a boundary condition, knowledge about the skills and interests of the addressees is required for realizing effective communication. The existing literature supports this proposed principle, highlighting the importance of the solver-oriented design of innovation challenges (Hossain 2018; Martinez and Walton 2014; Sieg et al. 2010) and their selective promotion (Boss et al. 2017; Fichter 2009; Zhu et al. 2019).

The final design principle, "mutual evolution", was derived when reflecting on the previous principles as well discussions with the involved practitioners. It stresses that all participants should harness multi-sided learning in order to jointly evolve the open innovation work system. For this purpose, processes and means to collect, share, and transform evidence concerning the functioning and multi-sided effects of the open innovation work system into evolutionary enhancements should be implemented. Prerequisites in this context include compatible expectations and trustful relationships between participants of the open innovation work system. In this regard, the role of co-evolutionary aspects such as shared learning (Randhawa et al. 2017; Schlagwein and Bjørn-Andersen 2014; Shao et al. 2012), relationship and community building 


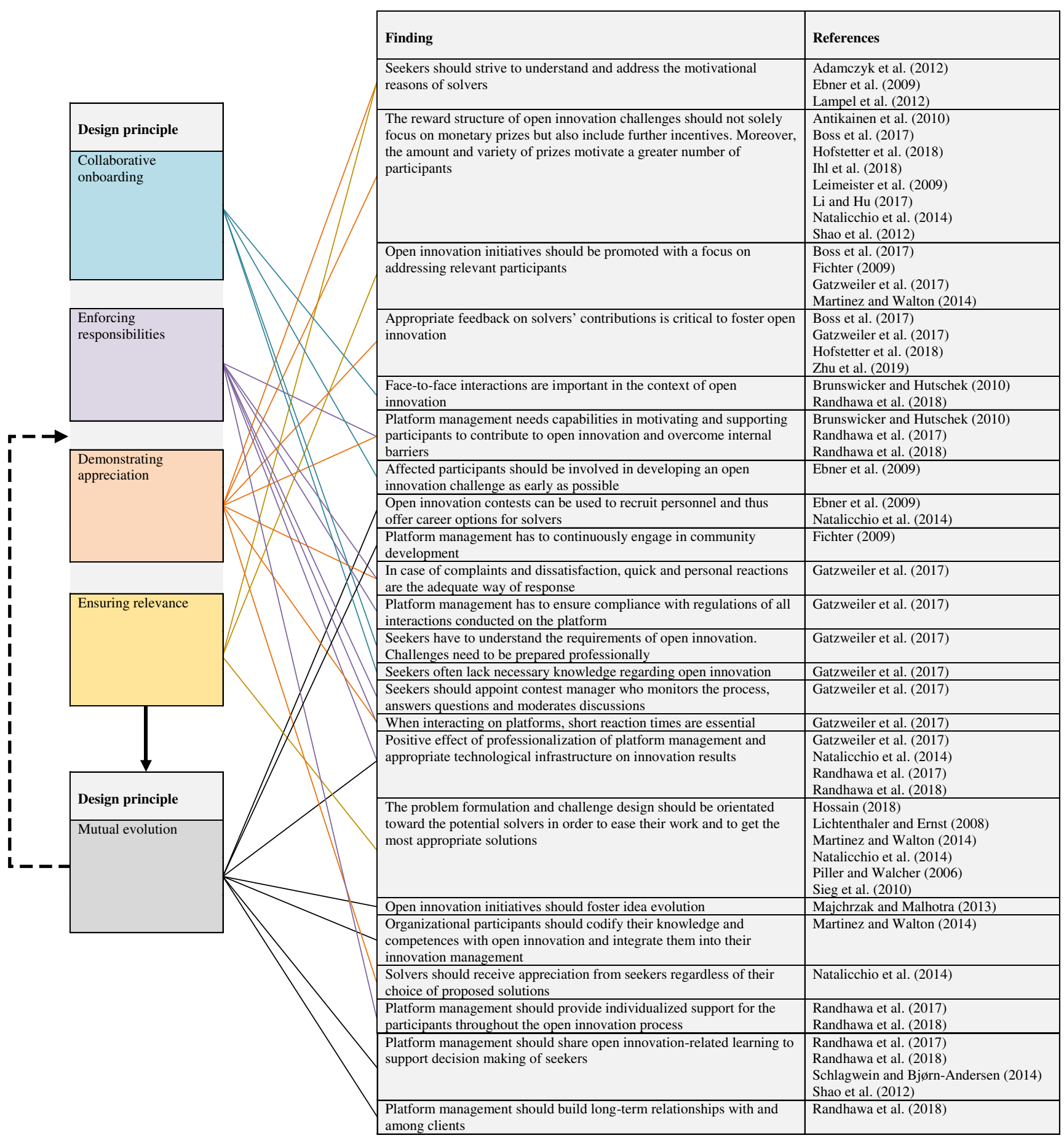

Fig. 3 Design principles in context with findings of existing literature

(Fichter 2009; Randhawa et al. 2018), and the mutual evolution of ideas (Majchrzak \& Malhotra, 2013) have received attention from scholars. As illustrated in Figs. 2 and 3, we propose that, over time, considering this principle may affect the context-dependent specification of actions, material properties, and boundary conditions that should be considered for onboarding collaboratively, enforcing responsibilities, demonstrating appreciation, and ensuring relevance. All in all, following Gregor's (2006) taxonomy of theory types, the proposed design principles contribute to nascent theory for design and action. We believe that the design principles present prescriptive knowledge that supports the establishment of multi-sided open innovation platforms in contexts where firms have no prior experience with this approach. Thus, we believe they are relevant for both scholars and practitioners alike. 


\section{Reflections on the WST-based system analysis}

Thinking of open innovation as a work system lifted the level of analysis and helped us overcome the focus on the technical artifact. It revealed that the multi-sided platform is merely a part of a larger system of realizing open innovation in the med tech cluster. This usage of WST applied a tool called "work system snapshot" and provided an outline for describing the initial conceptualization (Table 1) as well as the "to be" work system (Table 2). This straightforward representation provided the multidisciplinary action research team with a common guideline and language for design activities. In addition, it effectively structured the relevant topics in an orderly way. All stakeholders involved in the design and management of the work system could grasp its main ideas quickly and use it as a common basis for ideation. Also, it encouraged us to track any planned and unplanned system adaptations. The slot for participants helped us realize the different roles of the platform participants, while the slots for information and technologies made us think about the types of information and technologies that were important. The bulleted list of activities and processes forced us to discuss how the platform would operate, and the slots for products/services and customers helped us clarify what should be produced and for whom.

However, our use of WST revealed limitations of the work system snapshot as a tool, such as the fact that it assumes a relatively sequential process with few steps occurring parallelly. That limitation did not cause significant confusion when the work system snapshot was used for clarifying the scope of the work system during discussions and collaboration at the beginning of our action research project. However, we noticed that, if the analysis were required to become more detailed, it would have been necessary to use more detailed representations, such as flowcharts or activity diagrams that are more closely suited for representing detailed logic. While a highly detailed representation of the open innovation platform was not needed for our action research study, Table 2 shows that, for our purposes, a variation of the work system snapshot provides a more accurate representation than the simple work system snapshot in Table 1.

\section{Conclusion}

This paper explains how we conducted an action research study to address the question of what problems may arise in the process of systematically establishing a multi-sided open innovation platform in a med tech industry cluster in situations where firms had no prior experience with this approach and to identify how these problems may be overcome.

Our research studied how four successful open innovation projects operated and utilized a multi-sided open innovation platform provided by the cluster management in collaboration with further participants. This research contributes to literature focused on open innovation and multisided platforms by inductively developing five design principles and grounding them in literature focused on open innovation and platform design. These principles address the lack of constructive knowledge concerning the establishment of multi-sided open innovation platforms in contexts where firms had no prior experience with this approach. Moreover, we demonstrated that WST can be used as a useful analytical lens supporting the systematic establishment of open innovation initiatives overcoming the exclusive focus on the technical artifact (i.e., the multi-sided open innovation platform). WST helped us realize the platform is merely a part of a larger system that fosters open innovation in the investigated med tech cluster.

We found that, beyond the functional characteristics of technologies that were utilized, a key issue for successfully establishing a multi-sided open innovation platform is the management of expectations and interactions between the heterogeneous participants. It is crucial to engage both seekers and solvers continuously and to enforce roles and responsibilities. Despite being envisaged as an online platform-based approach, offline interactions are initially critical for fostering understanding in regard to open innovation. Moreover, personal discussions with an innovation consultant may help seekers identify actual innovation needs that may have not been previously obvious. Once a challenge is broadcasted via the open innovation platform, seekers' continuous feedback is of utmost importance. By promptly answering solvers' questions, seekers spur participation and ensure the proposed solution addresses the problem as accurately as possible. Thus, organizational and technological solutions ensuring seekers' feedback are vital for overall system performance.

The study produced progress toward opening the closed innovation approaches used by firms in a German cluster of excellence in the med tech field. However, the results must be considered in light of the study's limitations, which raise questions for future work. Since our open innovation work system was implemented in a regional cluster and evaluated through a limited number of cases, insights from our efforts are unlikely to be exhaustive. Following the proposed approach in other cases from different industries will create further knowledge regarding how to systematically and beneficially implement an open innovation platform. Furthermore, while the inductively derived design principles are in line with findings of existing literature (cf. Fig. 3), they have not been evaluated in a naturalistic setting. Therefore, future work is required to (dis)confirm the proposed design principles in different industrial contexts where firms have limited experience with open innovation. Moreover, future research should aim to gain a deeper understanding of how to 
measure and improve the effectiveness and efficiency of networked services and open innovation initiatives in general and related platforms in particular. Relevant indicators, models, and methods could be developed and evaluated in action design science research settings (Sein et al. 2011).

Acknowledgements We sincerely thank all contributors to this study. This study was funded by the Bavarian Ministry of Economic Affairs and Media, Energy and Technology (ZBNr: 0703/68668/13/2014).

Publisher's Note Springer Nature remains neutral with regard to jurisdictional claims in published maps and institutional affiliations.

\section{References}

Adamczyk, S., Bullinger, A. C., \& Möslein, K. M. (2012). Innovation contests: a review, classification and outlook. Creativity and Innovation Management, 21(4), 335-360. https://doi.org/10.1111/caim.12003.

Alam, I., \& Perry, C. (2002). A customer-oriented new service development process. Journal of Services Marketing, 16(6), 515-534. https://doi.org/10.1108/08876040210443391.

Alt, R., \& Klein, S. (2011). Twenty years of electronic markets research looking backwards towards the future. Electronic Markets, 21(1), 41-51. https://doi.org/10.1007/s12525-011-0057-z.

Alter, S. (2013). Work system theory: overview of core concepts, extensions, and challenges for the future. Journal of the Association for Information Systems, 14(2), 72-121.

Alter, S. (2015). Work system theory as a platform: response to a research perspective article by Niederman and March. Journal of the Association for Information Systems, 16(6), 485-514.

Antikainen, M., Mäkipää, M., \& Ahonen, M. (2010). Motivating and supporting collaboration in open innovation. European Journal of Innovation Management, 13(1), 100-119.

Baskerville, R., \& Myers, M. D. (2004). Special issue on action research in information systems: making IS research relevant to practiceforeword. MIS Quarterly, 28(3), 329-335.

Baskerville, R., \& Wood-Harper, T. (1996). A critical perspective on action research as a method for information systems research. Journal of Information Technology, 11(3), 235-246. https://doi. org/10.1080/026839696345289.

Bogers, M., Zobel, A. K., Afuah, A., Almirall, E., Brunswicker, S., Dahlander, L., ... Ter Wal, A. L. J. (2017). The open innovation research landscape: established perspectives and emerging themes across different levels of analysis. Industry and Innovation, 24(1), 8-40. https://doi.org/10.1080/13662716.2016.1240068.

Bogers, M., Chesbrough, H., \& Moedas, C. (2018). Open innovation: research, practices, and policies. California Management Review, 60(2), 5-16. https://doi.org/10.1177/0008125617745086.

Boss, V., Kleer, R., \& Vossen, A. (2017). Walking parallel paths or taking the same road? The effect of collaborative incentives in innovation contests. International Journal of Innovation Management, 21(3). https://doi.org/10.1142/S1363919617500244.

Brunswicker, S., \& Hutschek, U. (2010). Crossing horizons: leveraging cross-industry innovation search in the front-end of the innovation process. International Journal of Innovation Management, 14(4), 683-702. https://doi.org/10.1142/S1363919610002829.

Bullinger, A. C., Rass, M., Adamczyk, S., Möslein, K. M., \& Sohn, S. (2012). Open innovation in health care: analysis of an open health platform. Health Policy, 105(2-3), 165-175. https://doi.org/10. 1016/j.healthpol.2012.02.009.

BVMed. (2013). BVMed-Jahresbericht 2013/14. Berlin.
Chandra, L., Seidel, S., \& Gregor, S. (2015). Prescriptive knowledge in IS research: Conceptualizing design principles in terms of materiality, action, and boundary conditions. In Proceedings of the Annual Hawaii International Conference on System Sciences, pp. 4039 4048. https://doi.org/10.1109/HICSS.2015.485.

Checkland, P. (1991). From framework through experience to learning: the essential nature of action research. In H. Nissen, H. Klein, \& R. Hirschheim (Eds.), Information systems research: Contemporary approaches and emergent traditions (pp. 397-403). Amsterdam: Elsevier.

Chesbrough, H. (2003). Open innovation: the new imperative for creating and profiting from technology. Boston: Harvard Business School Press.

Chesbrough, H. (2006). Open innovation: a new paradigm for understanding industrial innovation. In H. Chesbrough, W. Vanhaverbeke, \& J. West (Eds.), Open innovation: Researching a new paradigm (pp. 1-12). New York: Oxford University Press.

Chesbrough, H., \& Rosenbloom, R. S. (2002). The role of the business model in capturing value from innovation: evidence from Xerox Corporation' s technology spin-off companies, Industrial and Corporate Change, 11(3), 529-555.

Dahlander, L., \& Gann, D. M. (2010). How open is innovation? Research Policy, 39(6), 699-709. https://doi.org/10.1016/j.respol.2010.01.013.

Davison, R. M., Martinsons, M. G., \& Kock, N. (2004). Principles of canonical action research. Information Systems Journal, 14(1), 6586.

Dyer, J. H., \& Singh, H. (1998). The relational view: cooperative strategy and sources of Interoganizational competitive advantage. The Academy of Management Review, 23(4), 660-679.

Ebner, W., Leimeister, J. M., \& Krcmar, H. (2009). Community engineering for innovations: the ideas competition as a method to nurture a virtual community for innovations. R\&D Management, 39(4), 342356. https://doi.org/10.1111/j.1467-9310.2009.00564.x.

Enkel, E., Gassmann, O., \& Chesbrough, H. (2009). Open R\&D and open innovation: exploring the phenomenon. $R \& D$ Management, 39(4), 311-316. https://doi.org/10.1111/j.1467-9310.2009.00570.x.

Ernst \& Young. (2017). As change accelerates, how can medtechs move ahead and stay there? Retrieved June 12, 2017, from http://www.ey. com/Publication/vwLUAssets/ey-medical-technology-report-2017/ \$FILE/ey-medical-technology-report-2017.pdf

Fichter, K. (2009). Innovation communities: the role of networks of promotors in open innovation. $R \& D$ Management, 39(4), 357371. https://doi.org/10.1111/j.1467-9310.2009.00562.x.

Gatzweiler, A., Blazevic, V., \& Piller, F. T. (2017). Dark side or bright light: destructive and constructive deviant content in consumer ideation contests. Journal of Product Innovation Management, 34(6), 772-789. https://doi.org/10.1111/jpim.12369.

Glaser, B., \& Strauss, A. (1967). The discovery of grounded theory: Strategies for qualitative research. Chicago: Aldine.

Goldkuhl, G. (2012). Pragmatism vs interpretivism in qualitative information systems research. European Journal of Information Systems, 21(2), 135-146. https://doi.org/10.1057/ejis.2011.54.

Gregor, S. (2006). The nature of theory in information systems. MIS Quarterly, 30(3), 611-642. https://doi.org/10.1080/ 0268396022000017725.

Habicht, H., Oliveira, P., \& Shcherbatiuk, V. (2013). User innovators: when patients set out to help themselves and end up helping many. Die Unternehmung, 66(3), 277-294.

Hallerstede, S. H. (2013). Managing the lifecycle of open innovation platforms. Wiesbaden: Springer.

Henkel, J. (2006). Selective revealing in open innovation processes: the case of embedded Linux. Research Policy, 35(7), 953-969. https:// doi.org/10.1016/j.respol.2006.04.010.

Hofstetter, R., Zhang, J. Z., \& Herrmann, A. (2018). Successive open innovation contests and incentives: winner-take-all or multiple prizes? Journal of Product Innovation Management, 35(4), 492517. https://doi.org/10.1111/jpim.12424. 
Holzmann, T., Sailer, K., \& Katzy, B. R. (2014). Matchmaking as multisided market for open innovation. Technology Analysis and Strategic Management, 26(6), 601-615. https://doi.org/10.1080/ 09537325.2014 .913786$.

Hossain, M. (2018). Motivations, challenges, and opportunities of successful solvers on an innovation intermediary platform. Technological Forecasting and Social Change, 128, 67-73. https://doi.org/10.1016/j.techfore.2017.10.018.

Huff, A. S., Möslein, K. M., \& Reichwald, R. (2013). Introduction to open innovation. In A. S. Huff, K. M. Möslein, \& R. Reichwald (Eds.), Leading open innovation (pp. 3-18). Cambridge: The MIT Press.

Hult, M., \& Lennung, S. (1980). Towards a definition of action research: a note and a bibliography. Journal of Management Studies, 17(2), 241-250.

Ihl, C., Vossen, A., \& Piller, F. (2018). All for the money? The limits of monetary rewards in innovation contests with users. International Journal of Innovation Management. https://doi.org/10.1142/ S1363919619500142.

Japsen, B. (2016). Medical technology sales to hit \$500B within five years. Retrieved July 7, 2017, from https://www.forbes.com/sites/ brucejapsen/2016/10/17/medical-technology-sales-to-hit-500bwithin-five-years/\#43f919011be1

King, N. (2004). Using templates in the thematic analysis of text. In C. Cassell \& G. Symon (Eds.), Essential guide to qualitative methods in organizational research (pp. 256-270). London: Sage.

Kohler, T., Fueller, J., Matzler, K., \& Stieger, D. (2011). Co-creation in virtual worlds: the design of the user experience. MIS Quarterly, 35(3), 773-788 Retrieved from http://live.bcps.org/web documents/RS/TheDesign of the User Experience (2011).pdf.

Krippendorff, K. (2013). Content analysis: An introduction to its methodology (3rd ed.). London: Sage.

Lakhani, K. R., Jeppesen, L. B., Lohse, P. A., \& Panetta, J. A. (2006). The value of openess in scientific problem solving, HBS Working Paper (No. 07-050).

Lampel, J., Jha, P., \& Bhalla, A. (2012). How design competitions are changing innovation. Academy of Management Perspectives, 26(2), $71-85$.

Laursen, K., \& Salter, A. (2006). Open for innovation: the role of openness in explaining innovation performance among U.K. manufacturing firms. Strategic Management Journal, 27(2), 131-150. https:// doi.org/10.1002/smj.507.

Lee, S., Park, G., Yoon, B., \& Park, J. (2010). Open innovation in SMEs - an intermediated network model. Research Policy, 39(2), 290-300. https://doi.org/10.1016/j.respol.2009.12.009.

Leimeister, J. M., Huber, M., Bretschneider, U., \& Krcmar, H. (2009). Leveraging crowdsourcing: activation-supporting components for IT-based ideas competition. Journal of Management Information Systems, 26(1), 197-224. https://doi.org/10.2753/MIS07421222260108.

Lettl, C., Herstatt, C., \& Gemuenden, H. G. (2006). Users' contributions to radical innovation: evidence from four cases in the field of medical equipment technology. $R \& D$ Management, 36(3), 251-272. https://doi.org/10.1111/j.1467-9310.2006.00431.x.

Li, D., \& Hu, L. (2017). Exploring the effects of reward and competition intensity on participation in crowdsourcing contests. Electronic Markets, 27(3), 199-210. https://doi.org/10.1007/s12525-017-0252-7.

Lichtenthaler, U., \& Ernst, H. (2008). Innovation intermediaries: why internet marketplaces for technology have not yet met the expectations. Creativity and Innovation Management, 17(1), 14-25. https:// doi.org/10.1111/j.1467-8691.2007.00461.x.

Lindgren, R., Henfridsson, O., \& Schultze, U. (2013). Design principles for competence management systems: a synthesis of an action research study. MIS Quarterly, 28(3), 435-472. https://doi.org/10. 2307/25148646.

Majchrzak, A., \& Malhotra, A. (2013). Towards an information systems perspective and research agenda on crowdsourcing for innovation.
Journal of Strategic Information Systems, 22(4), 257-268. https:// doi.org/10.1016/j.jsis.2013.07.004.

Martinez, M. G., \& Walton, B. (2014). The wisdom of crowds: the potential of online communities as a tool for data analysis. Technovation, 34(4), 203-214. https://doi.org/10.1016/j.technovation.2014.01.011.

Mathiassen, L., Chiasson, M., \& Germonprez, M. (2012). Style composition in action research publication. MIS Quarterly, 36(2), 347-363.

Mazzola, E., Acur, N., Piazza, M., \& Perrone, G. (2018). "To own or not to own?" A study on the determinants and consequences of alterantive intellectual property rights arrangements in crowdsourcing for innovation contests. Journal of Product Innovation Management, 35(6), 908-929. https://doi.org/10.1111/jpim.12467.

Möslein, K. M. (2013). Open innovation: Actors, tools, and tensions. In A. S. Huff, K. M. Möslein, \& R. Reichwald (Eds.), Leading open innovation (pp. 69-85). Cambridge: The MIT Press.

Nambisan, S. (2013). Information technology and product / service innovation: a brief assessment and some suggestions for future research. Journal of the Association for Information Systems, 14(4), 215-226.

Natalicchio, A., Messeni Petruzzelli, A., \& Garavelli, A. C. (2014). A literature review on markets for ideas: emerging characteristics and unanswered questions. Technovation, 34(2), 65-76. https://doi.org/ 10.1016/j.technovation.2013.11.005.

Piller, F. T., \& Walcher, D. (2006). Toolkits for idea competitions: a novel method to integrate users in new product development. $R \& D$ Management, 36(3), 307-318. https://doi.org/10.1111/j.1467-9310. 2006.00432.x.

Porter, M. E. (1998). Clusters and the new economics of competition. Harvard Business Review, 76(6), 77-90.

Powell, W. W., Koput, K. W., \& Smith-Doerr, L. (1996). Interoganizational collaboration and the locus of innovation: networks of learning in biotechnology. Administrative Science Quarterly, 41(1), 116-145.

Prock, T. (2017). And now for some good news... medtech remained the strongest sector for European patent filings last year. Retrieved March 27, 2018, from https://medtechengine.com/article/medtechpatents-2016/

PWC. (2013). Medtech companies prepare for an innovation makeover. Dellaware.

Randhawa, K., Josserand, E., Schweitzer, J., \& Logue, D. (2017). Knowledge collaboration between organizations and online communities: the role of open innovation intermediaries. Journal of Knowledge Management, 21(6), 1293-1318. https://doi.org/10. 1108/JKM-09-2016-0423.

Randhawa, K., Wilden, R., \& Gudergan, S. (2018). Open service innovation: the role of intermediary capabilities. Journal of Product Innovation Management, 35(5), 808-838. https://doi.org/10.1111/ jpim. 12460 .

Schlagwein, D., \& Bjørn-Andersen, N. (2014). Organizational learning with crowdsourcing: the revelatory case of LEGO. Journal of the Association for Information Systems., 15(11), 754-778. https://doi. org/10.17705/1jais.00380.

Sein, M. K., Henfridsson, O., Rossi, M., \& Lindgren, R. (2011). Action design research. MIS Quarterly, 35(1), 37-56.

Shao, B., Shi, L., Xu, B., \& Liu, L. (2012). Factors affecting participation of solvers in crowdsourcing: an empirical study from China. Electronic Markets, 22(2), 73-82. https://doi.org/10.1007/s12525012-0093-3.

Sieg, J. H., Wallin, M. W., \& Von Krogh, G. (2010). Managerial challenges in open innovation: a study of innovation intermediation in the chemical industry. R\&D Management, 40(3), 281-291.

Susman, G. I., \& Evered, R. D. (1978). An assessment of the scientific merits of action research. Administrative Science Quarterly, 23(4), 582-603.

Tan, B., Pan, S. L., Lu, X., \& Huang, L. (2015). The role of IS capabilities in the development of multi-sided platforms: the digital ecosystem 
strategy of Alibaba.com. Journal of the Association for Information Systems, 16(4), 248-280.

van de Ven, A. H. (2007). Engaged scholarship: a guide for organizational and social research. Oxford: Oxford University Press.

von Hippel, E. (2005). Democratizing innovation. Cambridge: MITPress.

West, J., \& Gallagher, S. (2006). Challenges of open innovation: the paradox of firm investment in open-source software. $R \& D$
Management, 36(3), 319-331. https://doi.org/10.1111/j.1467-9310. 2006.00436.

Zhu, H., Kock, A., Wentker, M., \& Leker, J. (2019). How does online interaction affect idea quality? The effect of feedback in firminternal idea competitions. Journal of Product Innovation Management, 36(1), 24-40. https://doi.org/10.1111/jpim.12442. 